\title{
Systemic Analysis for Inter-Relation of Identified Critical Success Factors in Enterprise Systems Projects
}

\author{
Vineet Kansal \\ Arab Open University \\ E-Mail: vineetkansal@yahoo.com
}

\begin{abstract}
While Enterprise Systems (ES) have the potential to offer benefits beyond traditional legacy systems, many organizations report that these have been less successful than originally anticipated. The difficulties of ES implementation have been widely cited in the literature but research on critical success factors (CSFs) for initial and ongoing ES implementation success is found to be fragmented. The paper presents an exploratory research study, where, particular ranked list of CSFs was first established and then used to analyze project performance in a case study of ES implementation in an airconditioning and refrigeration products industry. The CSFs identified were found to be helpful in investigating the causes for initial failure and subsequent success of the project. It was also observed that a change in attitude of top management, project management and users caused the success of the project. The study employed appropriate quantitative measures viz. statistical mean, reliability and content validity test for identification of CSFs. The case was studied using qualitative SAP-LAP (Situation-Actor-Process Learning-Action-Performance) framework, and Causal Loop Diagramming to extend the explanatory power of CSFs in a richer framework.
\end{abstract}

Keywords: Case Study, Enterprise Systems, ERP, Critical Success Factors

\section{INTROUDUCTION}

Enterprise Systems (ES) are presented as more effective and efficient ways of representing the knowledge necessary to manage the contemporary organization (Davenport et al., 2004). By adopting a process orientation and consequently integrating 
business processes by means of pre-engineered packaged software application, the stated goals of adopting ES are to obtain organizational benefits such as lower inventory costs and shorter cycle times (Holsapple \& Sena, 2005). Thus, ES tend to impose a specific logic of doing business, which is particularly shaped by the "best practices" that ES seek to bring with them (Motwani et al., 2002; Kraemmerand et al., 2003; Jones et al., 2004; Wagner \& Newell, 2005). Too often, project managers focus on the technical and financial aspects of a project and neglect to take into account the non-technical issues. To solve this problem some researchers are using the Critical Success Factors (CSFs) approach to study ES implementations. However, it is not yet clear how these CSFs interrelate leading to project success or failure.

This paper describes an exploratory research study where list of such factors has been identified and then was used to analyze the inter-relationship for a case of an ES implementation in an organization of air-conditioner and refrigeration product industry in India. This implementation at first experienced severe difficulties but turned around remarkably after a project crisis has resulted in changes in several of the CSFs for this case.

\section{LITERATURE REVIEW}

A cross-disciplinary literature review was conducted for better understanding of CSFs which are widely used in the information systems arena. It helped for defining CSF constructs and item generation for the study. The CSFs can be understood as the few key areas where things must go right for the implementation to be successful. Over the past few years, a considerable amount of research has been conducted in CSFs for ERP implementation. (Zhang et al., 2002; Nah et al., 2003; Umble et al., 2003; Somers \& Nelson, 2004; Dowlatshahi, S., 2005). Berchet \& Habchi, 2005, studied the integration and deployment of an ERP project at a telecommunication company. They proposed a five stage deployment model and described the risks, dysfunctions and the reasons for them. Gargeya \& Brady, 2005 identified that lack of appropriate culture and organizational (internal) readiness, project management as the most important factors contributing to success of ERP implementation. Sharma et al., 2006, identified various issues and challenges that might arise for ERP implementation in virtual enterprises.

A model of project implementation success is defined as $\mathrm{S}=\mathrm{f}(\mathrm{X} 1, \mathrm{X} 2, \ldots, \mathrm{Xn})$ when $\mathrm{S}$ is project success and Xi the CSF i (Slevin \& Pinto, 1996). The literature varies regarding which CSFs are required for implementation success or responsible for failure 
(Scheer \& Habermann, 2000; Wee, 2000; Al-Mashari et al., 2003). It is evident that they all do not work in isolation, without one CSF affecting another and vice versa. There is strong correlation between successfully implementing ERP and critical issues (Ehie \& Madsen, 2005). Al-Mashari et al. 2006, studied the essential issues that maximize ERP benefits and minimize its risks. The study proposed a road map for successful implementation. In the study of Yusuf et al. 2006, it was attempted to identify some Chinese specific difficulties in the implementation process and provide solutions to implementation ERP system successfully. It concluded some solutions eg. training, ERP software package selection, BPR, ERP implementation team and outsourcing application service provider; to overcome difficulties in ERP installation. The difficulties of ES implementation have been widely cited in literature but research on the critical success factors for initial and ongoing ES implementation success is found to be fragmented (Nah, et al, 2003). This motivated the researcher to explore critical factors and examine their inter-relationship that effect ES implementation project performance.

\section{RESEARCH METHODOLOGY}

A questionnaire was designed comprising CSF constructs using seven point Likert scale. The composite reliability estimates were used to assess the inter-item reliability. The list of such CSFs has been prepared in order of their importance using statistical mean ranking. This list was evaluated by 37 senior executive group members, comprising CIO, Managing Directors (MD), Vice Presidents (VP), project managers of the organizations in India that had gone through the process of ES implementation.

The case study was developed and analyzed using SAP- LAP framework (Sushil, 2000). The SAP (Situation, Actor, and Process) analyzes about current situation of the organization, the role played by actors involved and the process that deals with practice being adopted by the company for the ES project implementation. The LAP synthesizes the learning out of the process adopted, subsequent actions and performance of the project. The inter-play of identified CSFs in the case was observed using Causal Loop Diagramming Model (Senge, 1999; Sterman, 2000) to understand what lead to project into difficulties, and, the afterward towards success of the project.

For exploratory research, the case study is well known research method, though, certainly single case score low on generality of findings. However, the richness of data lends itself well for the inductive process of theory building. Further, in order to learn more about CSFs in ES implementation, it is needed to study at least two cases of high 
and low success keeping variables viz. size of organization, timeframe etc. identical. However, the case studied was sufficient in this case, as ample data were available where the project failed at first and succeeded at the same time.

\section{DISCUSSION}

\section{Identification of CSFs}

One of the goals of this study was to present reliable ranked list of CSFs constructs. The different CSFs were identified from the questionnaire survey of 92 organizations that have gone through ES implementation projects. The content validity of these constructs was tentatively established by extensive review with top executives and customers of technology mediated services. The composite reliability estimates greater than 0.70 was used to meet the criterion of reliability for these constructs. Some items were removed from the construct if their removal results in an increase in the reliability estimates, however, care was taken to ensure the validity of the measures is not threatened by the removal of a key conceptual element. The mean ranking of CSFs by the degree of importance in ES implementation is then prepared as shown in Table 1.

It can be seen from Table 1, that the 'top management support' was found to be a major CSF absolutely agreed by $74.6 \%$ respondents and statistical mean 5.54 , followed by other CSFs viz. 'user training \& education', 'BPR (Business Process Re-engineering) \& minimum customization', 'team competence', 'project management', organizational communication', clear goals \& objectives', 'change management', 'project champion', 'vendor support', 'user involvement \& participation', external consultant', and, 'suitability of technology'.

\section{Description of identified CSFs}

The CSFs identified as listed in Table 1 are then discussed which were found critical to ES implementation projects success.

Top Management Support is needed throughout the ES implementation. The project must align with strategic business goals. Top management support can play a useful role in setting disputes and in providing clear signals to any doubts that may arise. (Wee, 2000; Somers et al., 2004) They must be willing to allow for a mindset change by accepting that a lot of learning has to be done at all levels including themselves (Rao, 2000). 
User training and education refers to the process of providing management and employees with the logic and overall concepts of ES. The people can have a better understanding of how their jobs are related to other functional areas within the company. The user is the person who produces results and should be held accountable for making the system perform to expectations (Zhang et al., 2002).

Table 1 CSFs Reliability Values and Mean Ranking

\begin{tabular}{|c|c|c|c|c|c|c|c|}
\hline CSFs & $\begin{array}{l}\text { Absolutely } \\
\text { Agree }\end{array}$ & $\begin{array}{l}\text { Strongly } \\
\text { Agree }\end{array}$ & $\begin{array}{l}\text { To } \\
\text { Large } \\
\text { Extent }\end{array}$ & $\begin{array}{l}\text { Fairly } \\
\text { Agree }\end{array}$ & $\begin{array}{l}\text { Hardly } \\
\text { Agree }\end{array}$ & $\begin{array}{l}\text { Definitely } \\
\text { not Agree }\end{array}$ & $\begin{array}{l}\text { Cant' } \\
\text { Say }\end{array}$ \\
\hline & $(\mathrm{F} \%)$ & $(\mathrm{F} \%)$ & $(\mathbf{F \%})$ & $(\mathrm{F} \%)$ & $(\mathrm{F} \%)$ & $(\mathrm{F} \%)$ & $(\mathrm{F} \%)$ \\
\hline $\begin{array}{l}\text { Top management } \\
\text { Support } \\
(\text { mean }=5.54, \alpha=0.84)\end{array}$ & 74.6 & 14.3 & 7.6 & 2.3 & 0.0 & 0.0 & 1.2 \\
\hline $\begin{array}{l}\text { User Training \& } \\
\text { Education } \\
(\text { mean=5.21, } \alpha=0.78)\end{array}$ & 72.9 & 15.3 & 6.4 & 2.2 & 1.1 & 0 & 2.1 \\
\hline $\begin{array}{l}\text { BPR \& Minimum } \\
\text { Customization } \\
(\text { mean }=4.96, \alpha=0.80)\end{array}$ & 71.2 & 16.5 & 7.2 & 5.1 & 0 & 0 & 0 \\
\hline $\begin{array}{l}\text { Team Competence } \\
(\text { mean }=4.94, \alpha=0.79)\end{array}$ & 68.2 & 16.0 & 7.4 & 5.2 & 0 & 1.1 & 1.1 \\
\hline $\begin{array}{l}\text { Project Management } \\
(\text { mean }=4.86, \alpha=0.78)\end{array}$ & 62.6 & 20.2 & 5.2 & 9.4 & 1.2 & 0 & 1.4 \\
\hline $\begin{array}{l}\text { Organizational } \\
\text { Communication } \\
(\text { mean }=4.85, \alpha=0.81)\end{array}$ & 59.9 & 21.4 & 7.3 & 8.2 & 1.1 & 1.1 & 1.1 \\
\hline $\begin{array}{l}\text { Clear goals and } \\
\text { objectives } \\
(\text { mean=4.78, } \alpha=0.82)\end{array}$ & 55.4 & 38.6 & 1.5 & 3.4 & 0 & 0 & 1.1 \\
\hline $\begin{array}{l}\text { Change Management } \\
(\text { mean }=4.76, \alpha=0.80)\end{array}$ & 51.6 & 38.8 & 9.4 & 1.2 & 0 & 0 & 0 \\
\hline $\begin{array}{l}\text { Project Champion } \\
(\text { mean }=4.72, \alpha=0.77)\end{array}$ & 45.2 & 50.6 & 0 & 0 & 1.8 & 1.3 & 1.1 \\
\hline $\begin{array}{l}\text { Vendor support } \\
(\text { mean }=4.69, \alpha=0.75)\end{array}$ & 44.8 & 44.4 & 5.4 & 4.2 & 0 & 0 & 1.2 \\
\hline $\begin{array}{l}\text { User Involvement } \& \\
\text { participation } \\
(\text { mean=4.68, } \alpha=0.76)\end{array}$ & 40.9 & 49.4 & 1.2 & 5.2 & 1.1 & 0 & 2.2 \\
\hline $\begin{array}{l}\text { External consultant } \\
(\text { mean }=4.63, \alpha=0.75)\end{array}$ & 38.1 & 50.7 & 3.6 & 4.2 & 1.2 & 1.2 & 1.1 \\
\hline $\begin{array}{l}\text { Compatibility of } \\
\text { Technology } \\
(\text { mean=4.59, } \alpha=0.76)\end{array}$ & 37.4 & 49.4 & 4.6 & 4.2 & 1.2 & 2.1 & 1.1 \\
\hline
\end{tabular}

BPR and minimum customization is found an important CSF. It is inevitable that business processes are to be molded to fit the new system and aligning the business 
processes to software implementation is critical (Nah et al., 2001). Whenever and as far as possible, the ES hosting organization tries to adopt the process and options built into ES, rather, than seek to modify the ES to fit the particular business practices.

The project team competence is another important success factor for IS implementation (Stratman \& Roth, 2002). The ES project involves the entire functional department and demands the efforts and involvement of technical and business experts as well as the end users (Kumar \& Hillgersberg, 2000).

Project Management covers the project goal clarification and their congruence with organizational mission \& strategic goals. The scope should be established and controlled (Rosario, 2000). It must be clearly defined and be limited. Delivering early measures of success is important. A focus on result and constant tracking of schedules \& budgets against targets are important (Wee, 2000; Gargeya \& Brady, 2005).

Organizational Communication includes the sharing information not only between team members but also communicating to the whole organization the results and goals in each implementation stage. The communication is the oil that keeps everything working properly in IT project management (Schwalbe, 2000).

Clear goals and objectives are essential to guide ongoing organizational efforts for ES implementation. At the outset of ES implementation projects, it is often very difficult to determine these in crystal clear manner. This is why ES initiatives need to be considered as new business venture rather as IT projects. It is suggested to employ path based approach to ES implementation (Slevin \& Pinto, 1996).

Effective change management ensures the acceptance and readiness of the new system, allowing it to get the benefits and its use. A successful organizational change management approach relies in a proper integration of people, process and technology. Change management is important and has primary concern of IT project implementation (Somers et al., 2004). The recurring improvisational change methodology is a useful technique for identifying, managing and training changes in implementing ES project (Nah et al., 2003).

The role of project champion is critical to derive consensus and oversee the entire life cycle of implementation. The project champion is one who has power to set goals and legitimize change (Rosario, 2000). The role of project champion is very important for marketing the project throughout the organization (Somers et al., 2004).

It is important for the vendor's staff to be knowledgeable in both the business process and ES functions. Vendor should be carefully selected since vendor support play 
crucial role in shaping the ultimate outcome of implementation (Zhang et al., 2002). The project success is found to be positively associated with fit and compatibility with IT vendor employed.

User involvement \& participation refers to the behaviors and activities that users perform in the system process. It refers to a psychological state of the individual and is defined as the importance and personal relevance of a system to a user. There are two areas for user involvement when company tries to implement as ES system first, user involvement in stage of definition of company's ES system needs and, second, user participation in implementation of ES (Hartwick \& Barki, 1994).

Being ES implementation a complex process, it requires use of external consultants who are knowledgeable about installing the software. It is also revealed that during ES implementation, the consultant may be involved in different stages (Somers et al., 2004). The use of an external consultant depends on internal know-how that the organization has at the outset of the project

The compatibility of technology and company's needs must be carefully addressed as ES project involves a complex transition from legacy Information Systems and business processes to an integrated IT infra-structure and common business process throughout the organization (Al-Mashari, et al., 2003).

\section{The Case Study}

\section{Situation}

The company for this case study has been a pioneer in the air-conditioning and refrigeration products industry in India since 1926, with group turnover touching USD 45 million. The company offers product, ranges from basic air-conditioning to large Airconditioning (AC) projects, like AC Systems for oil sectors off and on-shore applications, as well as AC Systems for mobile and static radar communication for defense purpose. The company has an impressive clientele including major public sector organizations like Indian Railways, defense, telecommunication, oil sector, dairy products manufacturers and many other public and private sector organizations. It has designed and installed the air-conditioning system for the "outdoor broadcast" vans of Doordarshan, India's television network. Besides, it has developed air-conditioning for ships on the high seas. These are the first air conditioners of their kind as they use seawater for cooling the condenser. The company has developed a refrigerated cabinet for the storage of blood for 
use by the defense forces and blood banks. In addition, a part of the refrigeration of the Indian Mother Dairy milk booths of National Dairy Development Board has also been developed by the company. The company's internal and external environment can be summarized as in Figure 1.

\begin{tabular}{|c|c|}
\hline $\begin{array}{l}\text { S (Strengths) } \\
\text { - } \quad \text { Good brand equity } \\
\text { - } \quad \text { Excellent dealer network } \\
\text { - } \quad \text { Wide range of products } \\
\text { - } \quad \text { World class manufacturing plants } \\
\text { - } \quad \text { Strong R\&D facilities } \\
\text { - } \quad \text { Foreign joint venture }\end{array}$ & $\begin{array}{l}\text { W (weaknesses) } \\
\text { - } \quad \text { Global presence is low } \\
\text { - Lack of innovation in product design }\end{array}$ \\
\hline $\begin{array}{l}\text { O (Opportunities) } \\
\text { - Major presence in defense sector from } \\
\text { last } 30 \text { years } \\
\text { - Other government projects e.g. Metro } \\
\text { rail } \\
\text { - Brand and quality as uppermost } \\
\text { concern in the mind of consumers }\end{array}$ & $\begin{array}{l}\text { T (Threats) } \\
\text { - Government import policy } \\
\text { - High excise duty } \\
\text { - } \quad \text { Rising cost of inputs } \\
\text { - } \quad \text { Expectation of highly energy efficient, low / } \\
\text { zero noise, environment efficient product } \\
\text { One of joint venture company trying to } \\
\text { enter in India with other joint ventures }\end{array}$ \\
\hline
\end{tabular}

Figure 1 SWOT analysis

The company has seven manufacturing units and thirty four branches spread across India. The company has ambitious plans to foray into the promising markets of the Middle East and African countries. It also undertakes AC services and support assignments for their own, as well as competitor products through a separate arm. The company was found constantly leveraging its technological infrastructure in order to benchmark its operations and processes. In an attempt to strengthen its customer relationships and provide better customer services, the company has networked its branches and head office to enable efficient customer call handling, monitor product quality and receive direct feedback. The company has also signed a joint venture with Broad Corporation; China to manufacture gas based chillers.

The competitive nature of industry, non-availability and sharing of critical business information especially to top management were the primary reasons to go for an integrated solution. Further, the vastness of operations, remote locations of sales and service centers and foreign joint venture were the other factors to look for something new and innovative. To capture data of each location on site on time, fast information gathering and analysis, control of operations and cost of operations and eliminate 
redundancies it was planned to go for ES.

\section{Actors}

The chairman, MD, manufacturing unit heads and functional heads were the major actors involved in the process.

\section{Processes (ES Implementation)}

Based on market reports, cost, ease of implementation and Baan's already success in the same industry, the company decided to go for Baan as ES package. The company vision of looking inward and not do out of the box thinking, lead for vendor selection having focus on implementing ES for the processes as they were in use at the time.

The project implementation originally started in November 1999 and planned to be live by mid of year 2000 with finance, distribution, manufacturing, projects and quality assurance at Kalkaji, Delhi unit. As a contingency of Baan not delivering, customized reports were also prepared along-with Baan generated reports to keep the users happy. The parallel-run continued till December 2000. Afterwards, Noida and Bhiwadi unit heads were reluctant at that stage to go for huge investment in ES as Kalkaji unit was not still operational. In December 2000 due to Delhi government decision to close all manufacturing industry within the state, Kalkaji unit was forced to shut down. In December 2000, it was relocated to Noida with window fitted and split AC units of the company. It took around two months and there were no operations in that period. A number of key users (KU) and EDP (Electronic Data Processing) members left the organization. One of the major constraints for ES project now was the non-availability of $\mathrm{KU}$ of the type and caliber required. Hence, the implementation had to be done with very few KU available, and, in certain cases end users (EU) were assuming the role of KU, which was diluting the quality of project processes. So the project collapsed. Finally, in March 2001 due to the pressure for preparation of accounting books the company decided to go back to legacy system.

\section{Learning}

ES implementation project involves broad re-engineering. In conjunction with configuration, a large amount of re-engineering should take place iteratively to take advantage of improvements from the new system. ES project also integrate business function and resources. It is identified that 'change management' \& 'clarity of goals and 
objectives', 'User involvement \& participation' and 'organizational communication' are the core of ES implementation process (Figure 2).

These factors do reinforce each other as observed from this case. Similar findings are empirically observed that holds for teams in general, as small group research (McGrath, 1984). As the one goes up, then the other will increase as well as a result \& vice versa. Left to its own devices, this cycle will either continue to increase in ever better performance or decrease in never ending downward spiral of ever lower performance. The cause for poor performance of ES implementation project was analyzed using causal loop diagramming model (Figure 3).

It was learnt that top management support was poor in the organization. The top management failed to publicly and explicitly identify the project as the top priority. It was also observed that the top management was not fully committed in terms of involvement and providing needed people or other resources for implementation and giving appropriate amount of time to get the project done. A clear business model of how the organization should operate behind the project implementation was found missing due to poor support of management. Senior management was not pro-active in decision making. The functional area was not in a position to realize the importance of the outcome of the project. So they were least involved. Only the core project group was actively contributing to the project.

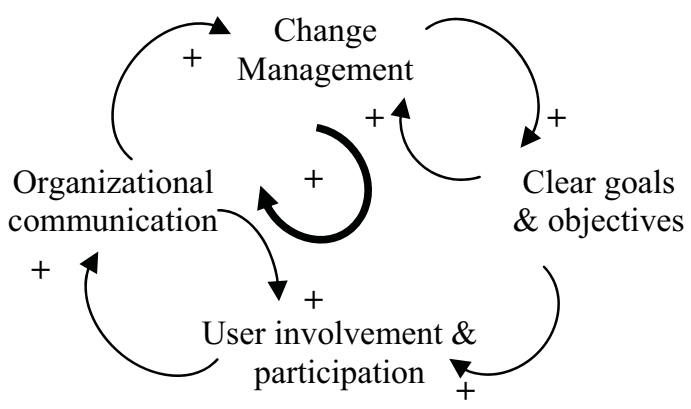

Figure 2 Core cycle in ES implementation project

The priorities of project team members with peer colleagues in the functional departments and the external consultant were misaligned. A culture with shared values and common aim is always conducive to project success. In this case, it was observed that the concern of team members was not addressed through proper organizational communication. It created the absence of a business plan that outlined the proposed 
strategic and tangible benefits, resources, cost, risk and timeline \& vice versa leading to poor project performance.

It was also observed that no individual or group of people was given responsibility to drive success in project management. Due to lack of vision clarity and poor change management of escalation of issues and conflicts resulted in the project occasionally coming to a halt. With this expectation mismatch, the project team members left the company. Treating end users as key users diluted the team's competence and, further, weakened the user involvement \& participation. It was also observed that there was poor vendor support and the external consultant was having focus on technology rather than the current business process. In order to complete the project, software was modified and molded to fit to existing business practices leading to further non clarity of goals \& objectives. The poor change management had no concern for user training and their education about how the system will change business process, system's impact and user role. It made it difficult to steer the direction of project as needed and resulted in a project mess.

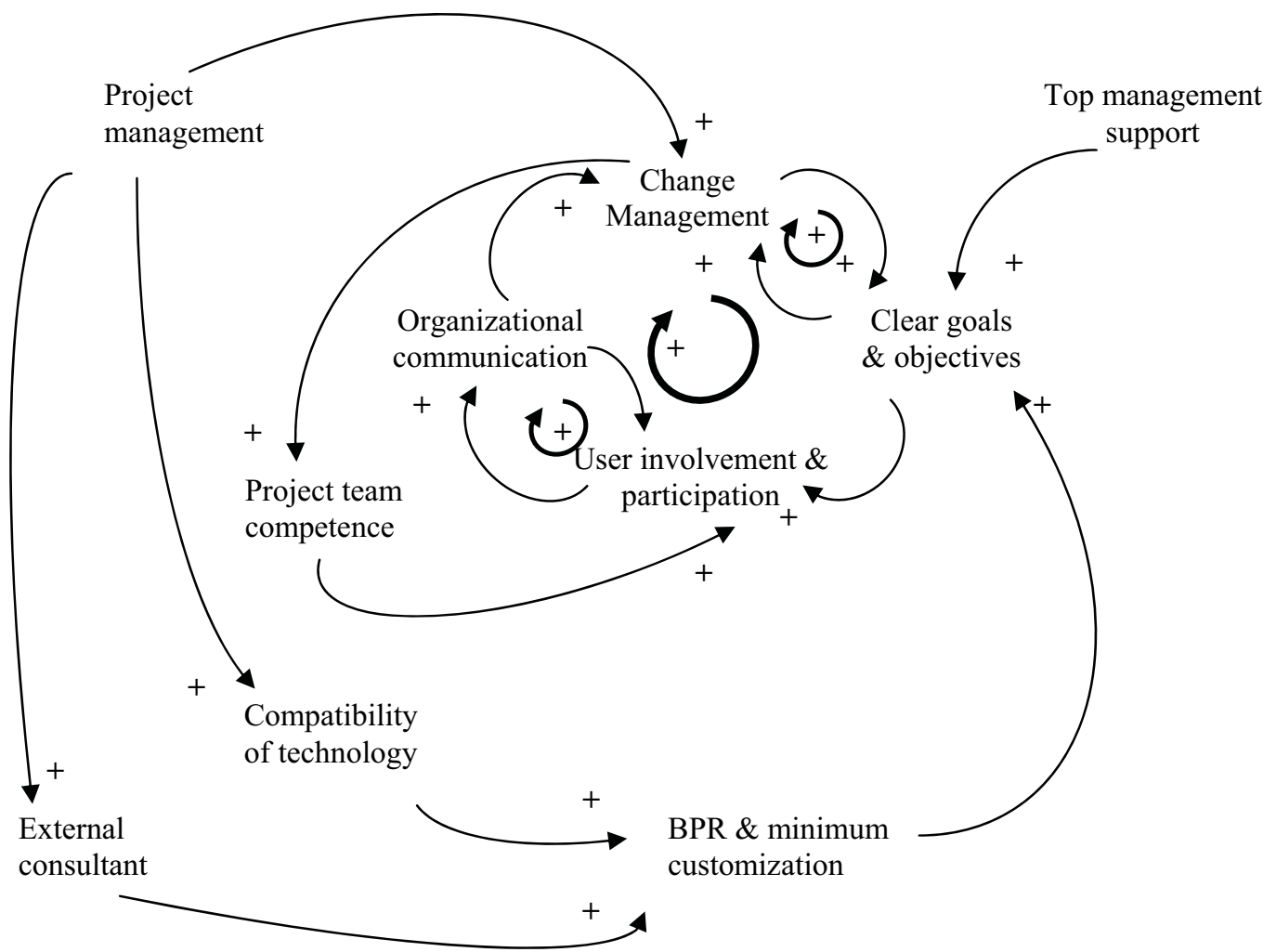

Figure 3 Causal loop diagram describing causes of poor performance 


\section{Action \& Performance}

During June 2001, as lot of money has already been invested, top management having understood the causes of failures took several strong measures turning a poor performing ES project to a success (Figure 4). The top management appointed experienced project manager with requisite the authority and command at the top position to carry out the project.

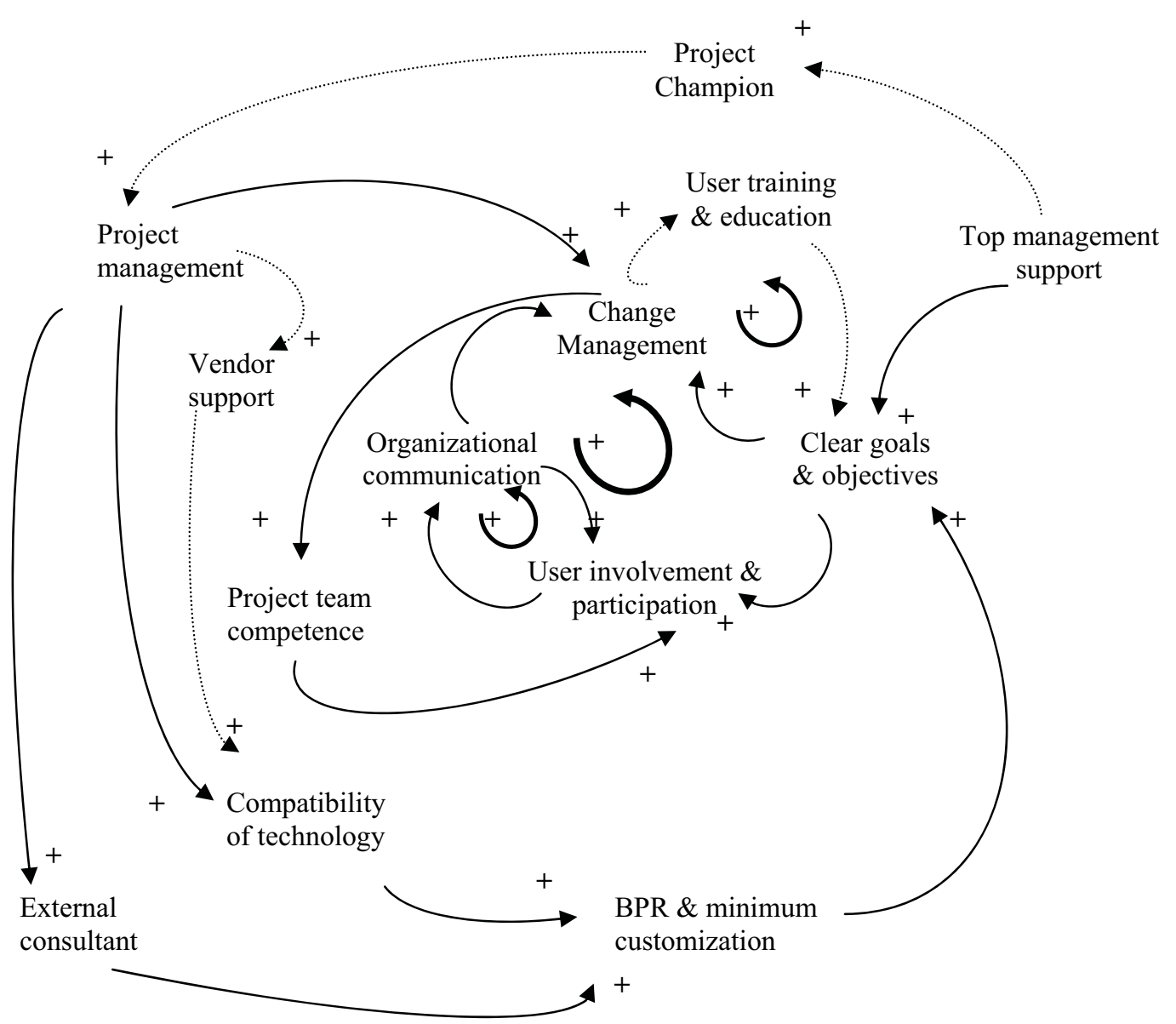

Figure 4 Causal loop diagram describing causes of ES project success

The project manager devised an effective project management strategy to control the ES implementation, avoiding overrun of budget and ensuring the implementation within schedule. The project plan defined project activities committed personnel to those activities, and promoted organizational support by the implementation process. Having 
framed sound change management plan, the implementation team was reconstituted having a mix of consulting company and internal cross functional staff.

The team members were given incentives for implementing system on time and within assigned budget. The company appointed one of the group IT company personnel having similar experience as external consultant to derive successful ES project in fixed timeframe. This time business process was the focus of the project. The vendor support actively sought. The technical discussions were conducted after understanding business processes had been made recorded. It ensured clarity of organizational goals and objectives.

A strong emphasis was given for user training \& education to increase the expertise and knowledge level of people within company. The multi-round and multi-tier training sessions were organized. It was intended to ensure that everyone understood why ES was necessary \& what changes it required. The training helped to overcome the fear for computing tools in managerial staff. The technical discussions were also conducted after proper understanding of business process. The proper organizational communication was ensured and top management also made themselves available as the need arose. This enhanced organizational communication and made user involvement a reality.

Finally, after ten months system came live. A company wide process improvement was started with cycle time reduction, information availability, and cost reduction and quality improvements as its primary objectives. As process has stabilized the Noida unit, the company planned to start implementation at Bhiwadi and Jabalbur units.

\section{CONCLUSION}

ES implementation project is a complex undertaking with a mix of success and failures (Al-Mashari et al., 2006). It embodies a complex implementation process, especially in developing countries like India, often taking several years, huge amount of funding and involving a major business process reengineering exercise. It is important to recognize the Critical Success factors that cause the project success. In this paper, an attempt has been made to identify some Indian and generally specific CSFs and their inter-relationship for ERP success. This study might be unusual because it consists of two episodes that are very different in their level of success. It may be learnt that it is possible to reverse a seemingly hopeless situation into a very successful one. Each of the changes described, may not has been enough alone to induce such a reversal of fortune, but 
collectively they certainly have been (Yusuf et al., 2006).

Because ERP systems are about integrating different business functions, 'organizational communication', and 'user participation \& involvement', 'change management' with 'clarity of goals \& objectives' were found to be the core processes for project progress. The presence and attitude of top management, project champion, project management (Gargeya \& Brady, 2005), vendor support, and, user training \& education were identified as the root causes driving performance of these core processes. The first contribution of the study was to provide a list of CSFs for an ES project as empirically found in Indian business context which was then applied to a specific case of ES implementation. The second contribution of the work was to show how these CSFs were interrelated and influenced each other directly or indirectly leading from poor performance to good performance of the project using causal loop diagramming models.

\section{REFERENCES}

Al-Mashari, M., Al-Mudimigh, A. \& Zairi, M. (2003). Enterprise resource planning: a taxonomy of critical success factors. European Journal of Operational Research, 146, 352-364.

Al-Mashari, M., Zairi, M., \& Okazawa, K. (2006). Enterprise resource planning (ERP) implementation: a useful road map. International Journal of Management and Enterprise Development, 3(1/2), 169-180.

Berchet, C. \& Habchi, G. (2005). The implementation and deployment of an ERP system: an industrial case study. Computers in Industry, 56(6), 588-605.

Davenport, T.H., Harris, J. G. \& Cantrell, S. (2004). Enterprise systems and ongoing process change. Business Process Management Journal, 10(1), 16-26.

Dowlatshahi, S. (2005). Strategic success factors in enterprise resource-planning design and implementation: a case study approach. International Journal of Production Research, 43(18), 3745-3771.

Ehie, I.C. \& Madsen, M. (2005). Identifying critical issues in Enterprise Resource Planning (ERP) implementation. Computers in Industry, 56(6), 545-557.

Gargeya, V.B. \& Brady, C. (2005). Success and failure factors of adopting SAP in ERP system implementation. Business Process Management Journal, 11(5), 501-516.

Hartwick, J. \& Barki, H. (1994). Explaining the role of user participation in information system use, Management Science, 40(4), 440-465.

Holsapple, C.W. \& Sena, M.P. (2005). ERP plans and decision support benefits. Decision 
Support Systems, 38, $575-590$.

Jones, M.C., Cline, M. \& Ryan, S. (2004). Exploring knowledge sharing in ERP implementation: an organizational culture framework. Decision Support Systems, article in press.

Kraemmerand, P., Moller, C. \& Boer, H. (2003). ERP implementation: an integrated process of radical change and continuous learning. Production Planning \& Control, $14(4), 338-348$.

Kumar, K. \& Hillegersberg, J.V. (2000, April). ERP experiences \& evolution. Communications of the ACM, 43(4), 23-26.

McGrath, J.E. (1984). Groups: Interaction and Performance, Prentice Hall, Englewood Cliffs. NJ.

Motwani J., Mirchandani D., Madan, M. \& Gunasekaran, A. (2002). Successful implementation of ERP projects: Evidence from two case studies. International Journal of Production Economics, 75, 83-96.

Nah, F.F., Zuckweiler, K.M. \& Lau, J.L. (2003). ERP implementation: chief information officers' perceptions of critical success factors. International Journal of Human Computer Interaction, 16(1), 5-22.

Rao, S. (2000). Enterprise resource planning: business needs and technologies. Industrial management \& Data Systems, 1000(2), 81-88.

Rosario, J.G. (2000). On the leading edge: critical success factors in ERP implementation projects. Business World, Philippines.

Scheer, A. \& Habermann, F. (2000). Making ERP a success. Communications of ACM, 43(3), 57-61.

Schwalbe, K. (2000). Information technology project management. Cambridge MA: Course Technology.

Senge, P.M. (1990). The fifth discipline: The art and practice of the learning organization. Doubleday Currency, New York.

Sharma, S.K., Chen C. \& Sundaram, S. (2006). Implementation problems with ERP systems in virtual enterprises / virtual organizations. International Journal of Management and Enterprise Development, 3(5), 491-509.

Slevin, D.P. \& Pinto, J.K. (1996). Critical success factors in successful project implementation. IEEE Transactions on Engineering Management, EM34(1), February 1987, 22-27.

Somers, T.M. \& Nelson, K.G. (2004). A Taxonomy of players and activities across the 
ERP project life cycle. Information \& Management, 41, 257-278.

Sterman, J.S. (2000). Business Dynamics: System thinking and modeling for a complex world. McGraw Hill, New York.

Stratman, J.K. \& Roth, A.V. (2002). Enterprise resource planning (ERP) competence constructs: two stage multi-item scale development and validation. Decision Sciences, 33(4), 601-626.

Sushil. (2000). SAP- LAP models of inquiry, Management Decision, 38(5), 347-353.

Umble, E.J., Haft, R.R. \& Umble, M.M. (2003). Enterprise resource planning; implementation procedures and critical success factors. European Journal of Operational Research, 146, 241-257.

Wagner, E.L. \& Newell, S. (2005). 'Best' for whom? The tension between 'best practice' ERP packages and diverse epistemic cultures in a university context. Journal of Strategic Information Systems, article in press, 1-24.

Wee, S. (2000, February). Juggling towards ERP success: keep key success factors high, ERP News (http://www.erpnews.com/erpnews/erp904/02get.html).

Yusuf, Y., Gunasekaran, A. \& Wu, C. (2006). Implementation of enterprise resource planning in China. Technovation.

Zhang, L., Zhang Z. \& Banerjee, P. (2002). Critical success factors of enterprise resource planning systems implementation success in China, 36th Hawaii international conference on System sciences, IEEE. 